\title{
Inbaltsverzeidnis.
}

Gette Bortoort .............. VII

\section{Mrgemetuer Teil.}

1. Rahrungomittelgefé vom 14. Mai 1879. (Tubgug.) 1

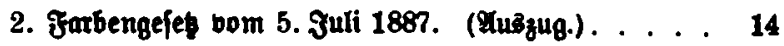

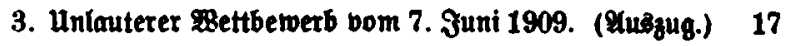

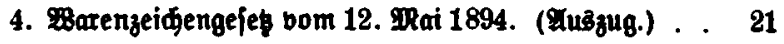

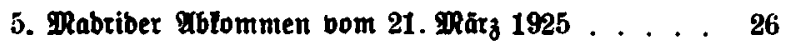

6. Berjailfer Bertrag, Grtilel 274 unb $275 \ldots . . .31$

7. Belanntmađ̆ung, betr. äuß̧ere Fennzeidnung ber Baten, boin 18. Mai 1916. . . . . . . . . 32

8. Betanntmađung, betr. irteführente Bezeiđunung ber Rahrunge- unb Benufmittel, vom 26. Эuni 1916. . 34

\section{Wetin, weinäbnlihe, weinhaltige Cettunte.}

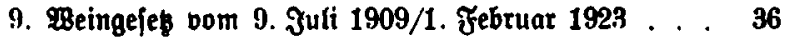

10. Tuşüurungafeftimmungen zum Beingejes in ber

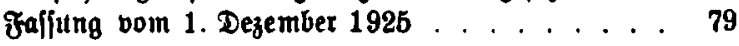

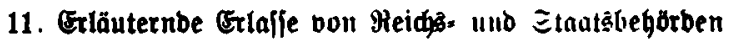
zum 28 eingefés. . . . . . . . . . . 99 93

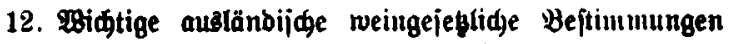
mit beutid-portugiejif hem . panbelovertrag . . . . . 107

13. Beinzollorbnung bom 17. ̧̧uli 1909 unb Ergä॥zungen. (2Tisgugatweife.) . . . . . . . . . . . . 114 
3ungaltôberzeidnis.

14. \$einfteuergeies vom 16. Fuguft 1925 . . . . . . . 122

15. Tusfürungsbeftimmungen zum 2 einfteuergejes. (Ius: zugstoeife.).

\section{Biet unb biexdynltige Betränte.}

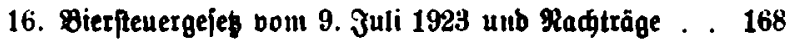

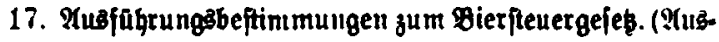
zugweife.) . . . . . . . . . . . . . 200

\section{Brauntwein und Iriutbranutwein.}

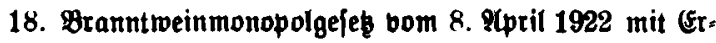
gănzungen . . . . . . . . . . . . 214

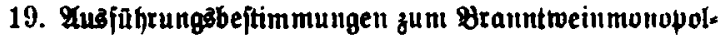

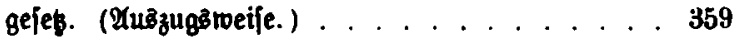

a) Brunbbeftimmungen . . . . . . . . . . . . 359

b) Brennereiorbnung . . . . . . . . . . . . . . 361

c) Berwerturgsorbnung . . . . . . . . . . 372

d) Berorbnungen, betteffent ben Budführungsztoang 380

e) Zeønifde Beftimmungent . . . . . . . . . 380

20. Betauntmađung bom 18. Juni 192.2, betr. MRinbeftaltoholftărfe von Irintbranntroeiu. . . . . . . 382

21. 2abjintbgelég vom 23 . april $1923 \ldots \ldots$. . . . 383

\section{Roblenjaure Cetränte.}

2.. Rormalentrurf bes Bunbesints vom 9. Rovember $1911 \ldots \ldots 38$

23. Betorbiung vom 20. Ottober 1901. (Rlı̈zug.) . . 392

Alphabetifdez Jubaltoverzeidniz... 393 